Classification

Physics Abstracts

42.30.Sy $-81.90 .+\mathrm{c}$

\title{
Quantification of Particle Morphology in Powder Process Technology
}

\author{
Hervé Vivier, Marie-Noëlle Pons, Bruno Bernard-Michel, Thierry Rolland, \\ Laurence Voignier and Marijan Vucak \\ Laboratoire des Sciences du Génie Chimique, CNRS-ENSIC-INPL, 1 rue Grandville, BP 451, \\ 54001 Nancy Cedex, France
}

\begin{abstract}
Résumé. - Des méthodes de quantification de la morphologie bi- et pseudo tri-dimensionnelle de particules présentant un large spectre de forme et de structure sont présentées. Ces méthodes sont appliquées pour mieux comprendre les phénomènes intervenant dans différents procédés mis en oeuvre en technologie des poudres (précipitation, cristallisation, broyage).
\end{abstract}

\begin{abstract}
Methods of quantification of 2D- and 3D morphology for particles presenting a broad spectrum of shape and structure are described. Their application yields to a better understanding of the phenomena taking place in various particle technology processes (precipitation, crystallization, grinding).
\end{abstract}

\section{Introduction}

Morphology is becoming a key-word in powder technology as this characteristic affects many enduse properties of the final products. It controls filtrability of slurry, flowability and compressibility of powders [1], grindability [2]....

In precipitation and crystallization morphology can be modified by varying operation conditions such as concentration of reactants, presence of additives or impurities, temperature, viscosity, reactor design (mixing characteristics, position of feed jets) or control (adjustment of reactant feedrates). In grinding processes the examination of fragments help to understand the size reduction phenomena (fracture, attrition, shearing): these equipments are large consumers of energy and such knowledge is useful in the design of more efficient mills and the selection of their operation parameters. The strength of tablets, which are obtained by compression of powders, is related to the structure oi the stackings of grains, defined, in part, by the morphology of the individual particles.

Morphology is assessed, first qualitatively, secondly quantitatively by visualization of the particles. Light and electron microscopy are largely employed for that purpose. Analysis of the images should then be used to provide a quantitative description of the individual crystals. The shape 
descriptors can later be averaged over a set of particles. Their time-dependence give eventually an information on the morphology kinetics.

2D shape descriptors are generally based on the silhouette of the particle [3] or on its contourline [3-8]. Relief images obtained by a binocular or a scanning electron microscope can provide information on the $3 \mathrm{D}$ structure.

The purpose of this contribution is to show how the quantitative description of the morphology crystalline particles can give a better insight into powder technology processes.

\section{Materials and Methods}

Hydrargillite particles of the radial type (HR) and the mosaic type (HM) have been provided by Pechiney Company, France and Alcoa of Australia, respectively. Copper sulfate crystals have been grown in a 20-liter reactor, operated discontinuously. Commercial sugar crystals (white beet sugar, brown and white cane sugars) have been purchased.

Calcium oxalate has been precipitated by mixing a potassium oxalate solution and a calcium chloride solution in a well-stirred 0.4-liter reactor. Barium sulfate crystals have been obtained in the same reactor by mixing a barium chloride solution and a sodium sulfate solution. The precipitate crystals are filtered and dried on Sartorius cellulose nitrate membranes $(0.2 \mu \mathrm{m}$ pore size).

For examination by light microscopy crystals are deposited on a glass slide and observed with a Leitz Dialux ${ }^{\mathrm{TM}} 20$ microscope equipped with a Bosch ${ }^{\mathrm{TM}}$ tube camera connected to a Sfg2200 board located into a SUN Sparc LX ${ }^{\mathrm{TM}}$ workstation. 8-bit grey-level images of $768 \times 576$ square pixels are captured (image A).

For examination by scanning electron microscopy, crystals or pieces of membrane are deposited on the sample holders covered with double-sided tape. After gold-plating the samples are observed with a Jeol TM $330 \mathrm{~A}^{\mathrm{TM}}$ SEM (secondary electron) connected to a PC-compatible via a ImageSlave ${ }^{\mathrm{TM}}$ board (Meeco, Melbourne, Australia) for direct capture of digital images. Images are later sent via the computer network to the workstation. 8-bit grey-level images of $592 \times 391$ square pixels are captured (image $\mathrm{A}^{\prime}$ ). A professional image analysis software Visilog $^{\mathrm{TM}} 4.1 .4$ (Noésis, Orsay, France) and lab-developed software are used.

For SEM images, after image enhancement by morphological gradient of the grey-level image $\mathrm{A}^{\prime}$ (Fig. 1a), automatic threshold, manual correction of the contour (when necessary) with the cursor $(\rightarrow$ image $C$ ) and hole filling, a binary image B is obtained: it contains the crystal silhouette (Fig. 1b). A logical operation between $B$ and $C$ provides image $D$ containing the particle facets: $\mathrm{D}=\mathrm{B}-\mathrm{C}$ (Fig. 2a). Good contrast is achieved with the light microscope: a threshold of image $A$ at a preset value is sufficient to obtain, after hole filling and removal of debris (erosion + reconstruction procedure) and objects in contact with the image frame, the binary image B. The particle borderline is calculated from image $\mathrm{B}$ and vectorized: the particle convex hull $\mathcal{H}_{\mathrm{c}}$ (image E) is determined from the obtained set of vectors (Fig. 1c).

\section{Shape Characterization}

3.1 2D-DESCRIPTORS. - Primary descriptors are computed on the particle silhouette (image B, Fig. 1b): surface $S$, from which $D_{\text {eq }}=2 \sqrt{S / \pi}$ is deduced, perimeter $P$, Feret diameters distribution, from which the maximal $\left(F_{\max }\right)$ and minimal $\left(F_{\min }\right)$ diameters are deduced to give measurements of the particle "length" and "breadth" respectively. Secondary parameters are calculated: circularity $C=P^{2} /(4 \pi S)$, elongation $\left(F_{\max } / F_{\min }\right)$ and aspect ratio $\left(F_{\max } / D_{\text {eq }}\right)$ are calculated. 


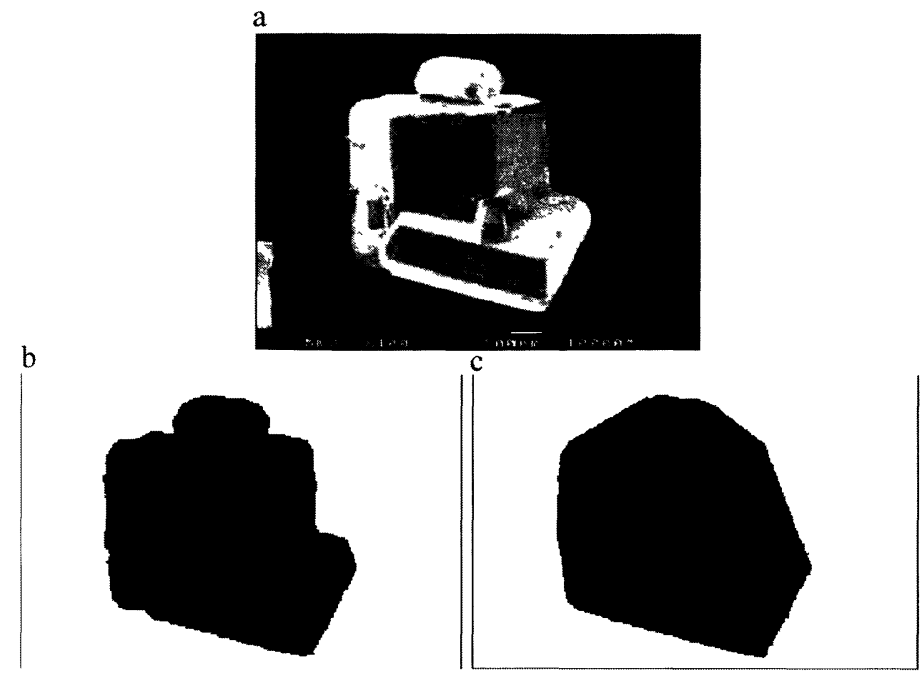

Fig. 1. - a) Grey-level image $A^{\prime}$ (white cane sugar). b) Binary image $B=$ silhouettes. c) Binary image $\mathrm{E}=$ convex hull $\mathcal{H}_{\mathrm{c}}$.

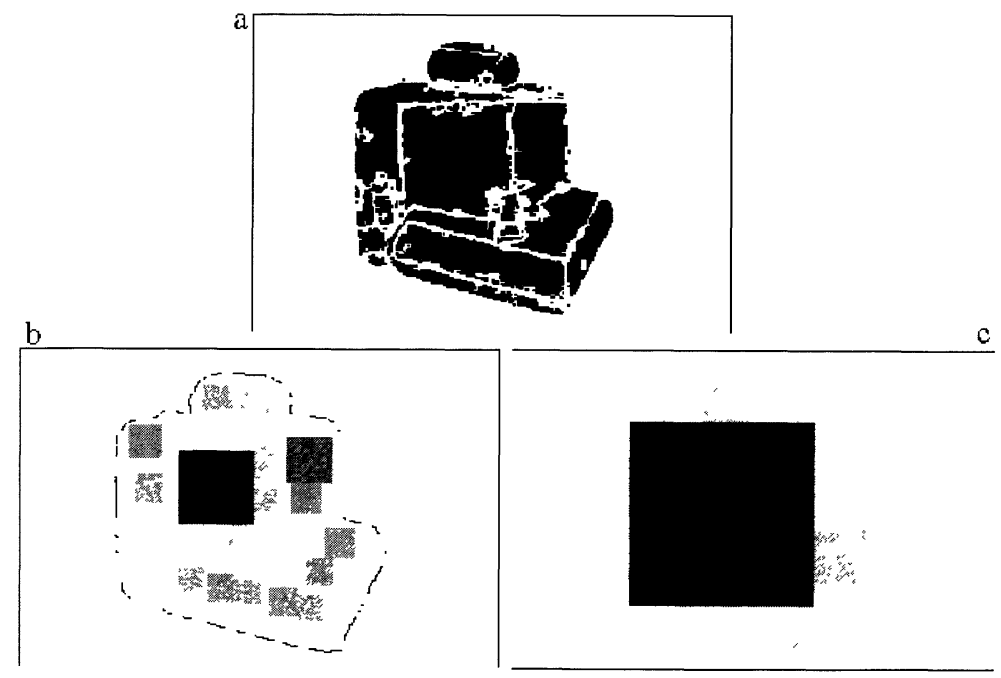

Fig. 2. - a) Binary image $D=$ facets; coverage of $D(b)$ and $B(c)$ by sets of squares.

The particle silhouette is compared to its convex hull $\mathcal{H}_{\mathrm{c}}$ (image E, Fig. 1c). Let $\omega_{1}$ and $\omega_{2}$ be, respectively, the number of erosions necessary to eliminate completely the particle silhouette and its residual set with respect to $\mathcal{H}_{\mathrm{c}}$ (of surface $\mathrm{S}_{\mathrm{c}}$ ). Two size-invariant shape descriptors are computed: $\Omega_{1}=2 \omega_{1} / \sqrt{S}$, which characterizes the particle robustness and $\Omega_{2}=2 \omega_{2} \sqrt{S}$, which measures the largest concavity. A surface concavity index, which quantifies globally the silhouette concavity is also computed: $\mathrm{CI}=S / S_{\mathrm{c}}$.

3.2 Pseudo 3D Descriptor. - The partition-in-squares is based on the distribution of squares inscribed in an object (in the case ofthe particle silhouette) or a set of objects in the case of 


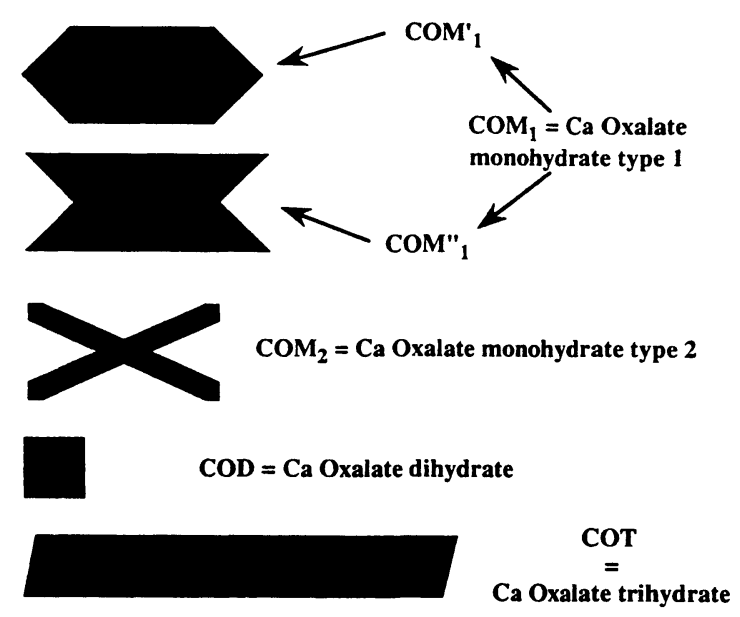

Fig. 3. - Silhouettes of calcium oxalates crystals.

the particle facets) (image D, Fig. 2a). The principle is to divide the zones between edges (borderline, facet edges) into squares of increasing size, so that the total available area is covered. This procedure is performed on the facet image $\mathrm{D}$ and on the silhouette image $\mathrm{B}$ and results in distributions $f(x)$ of squares of side length $x$, aligned with the image grid (Figs. 2b and 2c). The cumulative frequency distributions are given by:

$$
F_{\text {facet }}(u)=\int f_{\text {facet }} \mathrm{d} u \text { and } F_{\text {silhouette }}(u)=\int f_{\text {silhouette }} \mathrm{d} u
$$

where $u$ is the normalized side length: $u=x / \sqrt{S}$. A size and position invariant simplicity index $\xi$ is computed:

$$
\xi=\frac{\int\left(1-F_{\text {facet }}(u)\right) \mathrm{d} u}{\int\left(1-F_{\text {silhouette }}(u)\right) \mathrm{d} u} .
$$

The side length of the largest square inscribed in the facets is $X_{\max }$.

\section{Results}

4.1 Precipitation. - Precipitation processes are very sensitive to mixing conditions in the reactor [9]. In many cases 2D-descriptors are sufficient to distinguish between crystal habits [10]. Calcium oxalate crystals are such an example (Fig. 3). $\mathrm{COM}_{1}^{\prime}$ and $\mathrm{COM}_{1}^{\prime \prime}$ correspond to the same crystals but resting on a different facet: both facets yield to an equivalent stability position of the. crystal on the membrane. The combination, through a Principal Components Analysis procedure, of aspect ratio, $\Omega_{1}, \Omega_{2}$ and CI yields to a representation in the $\mathrm{f}_{1}-\mathrm{f}_{2}$ space of a set of 80 crystals obtained in experiments run under different strategies for $\mathrm{CaCl}_{2}$ feeding (Fig. 4): $\mathrm{f}_{1}$ and $\mathrm{f}_{2}$ are the two major principal components, used to more than $90 \%$ of the total variance.

In the case of other precipitations such as the one of $\mathrm{BaSO}_{4}, 2 \mathrm{D}$-descriptors may not be sufficient to provide a complete description of the particles. The inclusion of $\xi$ in the set of shape descriptors is useful to discriminate between the different pyramidal shapes shown in Figure 5 (Tab. I). 


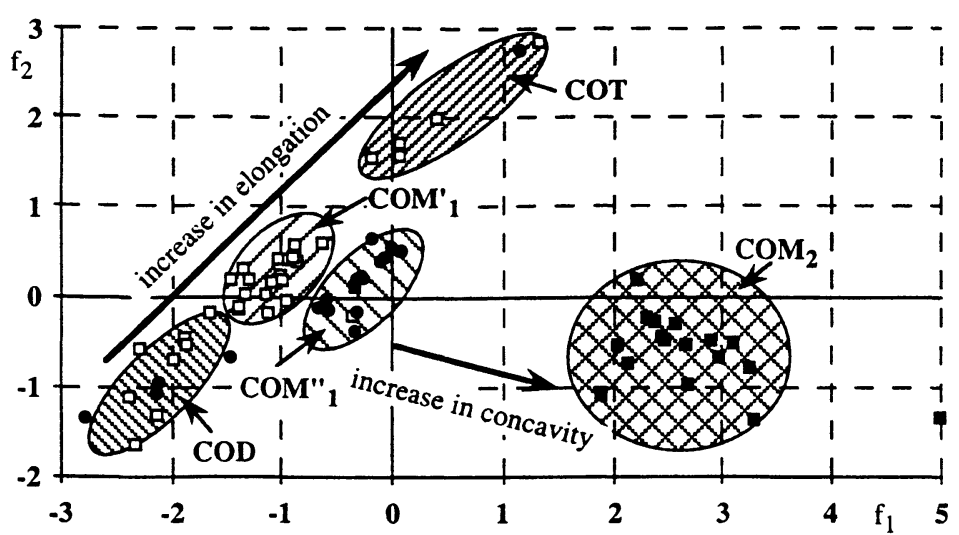

Fig. 4. - Localization of calcium oxalates in the principal components space.
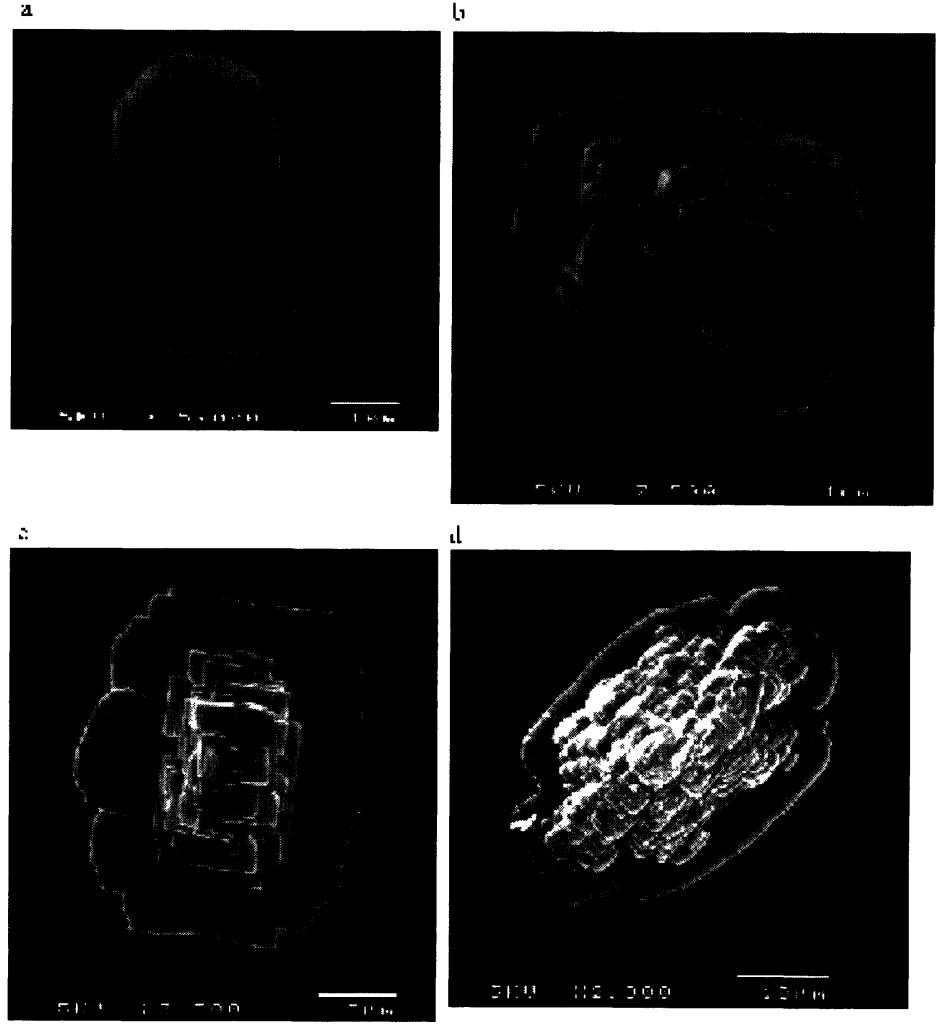

Fig. 5. - Types of barium sulfate crystals.

4.2 CRYStallization. - In crystallization processes the presence of impurities in the solutions induces the modification of the crystal habits. In the case of sugar, substances such as dextrane or raffinose are known to affect the elongation of sucrose crystals. The degree of agglomeration is also important to assess the product quality (Figs. 1a and 6). Table II summarizes the results obtained by optical microscopy and SEM on three different kinds on sugar crystals. A careful 
Table I. - Shape descriptors of $\mathrm{BaSO}_{4}$ crystals pictured in Figure 5.

\begin{tabular}{|c|l|l|c|c|c|}
\hline Crystal & $C$ & $F_{\max } / D_{\text {eq }}$ & $\Omega_{1}$ & $\Omega_{2}$ & $\xi$ \\
\hline $\mathrm{a}$ & 1.2 & 1.32 & 0.65 & 0.02 & 1 \\
\hline $\mathrm{b}$ & 1.11 & 1.15 & 0.77 & 0.03 & 0.33 \\
\hline $\mathrm{c}$ & 1.21 & 1.16 & 0.82 & 0.04 & 0.28 \\
\hline $\mathrm{d}$ & 1.28 & 1.27 & 0.66 & 0.06 & 0.11 \\
\hline
\end{tabular}

Table II. - Comparison of the morphology of three populations of sugar crystals. The variability is given in italics.

\begin{tabular}{|c|c|c|c|c|c|c|}
\hline & \multicolumn{3}{|c|}{$\begin{array}{r}\text { Scanning Microscopy } \\
(25 \text { ind./sample) }\end{array}$} & \multicolumn{3}{|c|}{$\begin{array}{r}\text { Optical Microscopy } \\
(200-300 \text { ind./sample })\end{array}$} \\
\hline Sugar & $D_{\text {eq }}(\mu \mathrm{m})$ & $C$ & $\xi$ & $D_{\text {eq }}(\mu \mathrm{m})$ & $C$ & $\%$ agglom. \\
\hline White cane & 830 & 1.56 & 0.31 & 760 & 1.42 & 56 \\
& $(12 \%)$ & $(7 \%)$ & $(25 \%)$ & $(8 \%)$ & $(8 \%)$ & \\
\hline Brown cane & 1080 & 1.44 & 0.47 & 720 & 1.44 & 32 \\
& $(23 \%)$ & $(9 \%)$ & $(30 \%)$ & $(17 \%)$ & $(9 \%)$ & \\
\hline Beet & 1100 & 1.53 & 0.45 & 950 & 1.40 & 45 \\
& $(15 \%)$ & $(10 \%)$ & $(40 \%)$ & $(13 \%)$ & $(8 \%)$ & \\
\hline
\end{tabular}

selection of the shape descriptors should be made: discrimination between monocrystals, and twinned crystals or agglomerates is not possible based solely on a parameter such as $C$ (circularity), which includes information on both elongation and concavity. On the contrary a degree of agglomeration can be computed based on $\Omega_{2}$, as the agglomerates are concave particles:

$$
\text { \%agglom. }=\frac{\text { nb. crystals with } \Omega_{2}>0.05}{\text { total nb. crystals }} .
$$
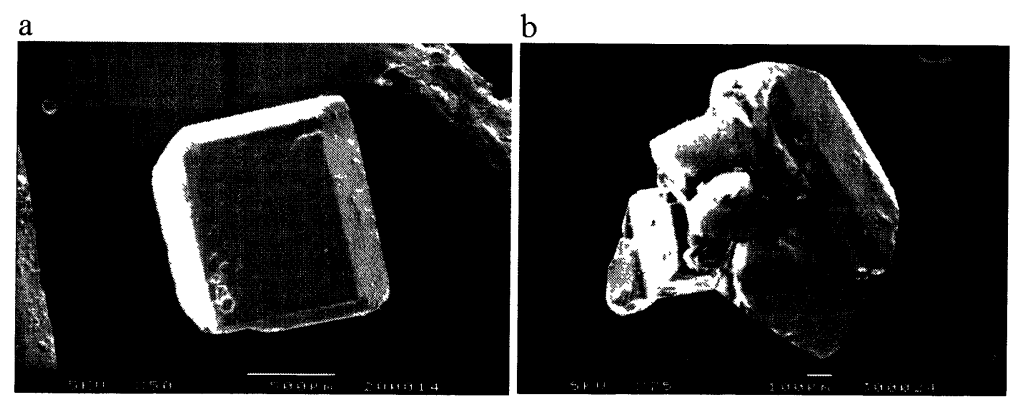

Fig. 6. - Sugar: a) brown cane sugar; b) beet sugar. 


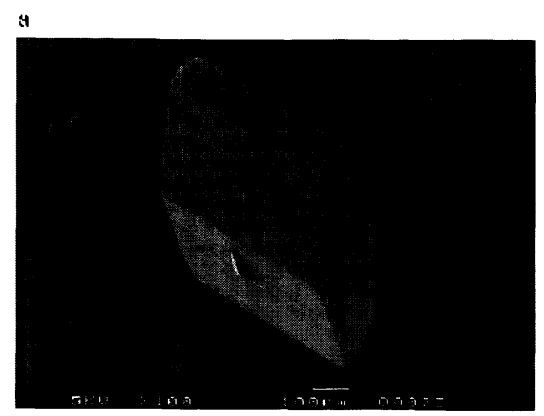

b

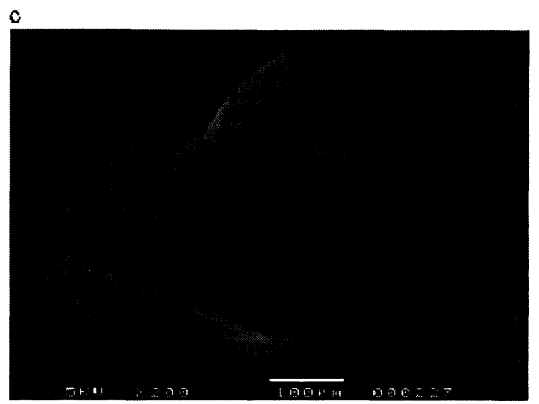

Fig. 7. $-\mathrm{CuSO}_{4}$ : a) $\mathrm{CI}=0, \xi=0.86$, elongation $=1.46$; (b) $\mathrm{CI}=0.14, \xi=0.49$, elongation $=1.23$; (c) $\mathrm{CI}=0.16, \xi=0.29$, elongation $=1.22$.
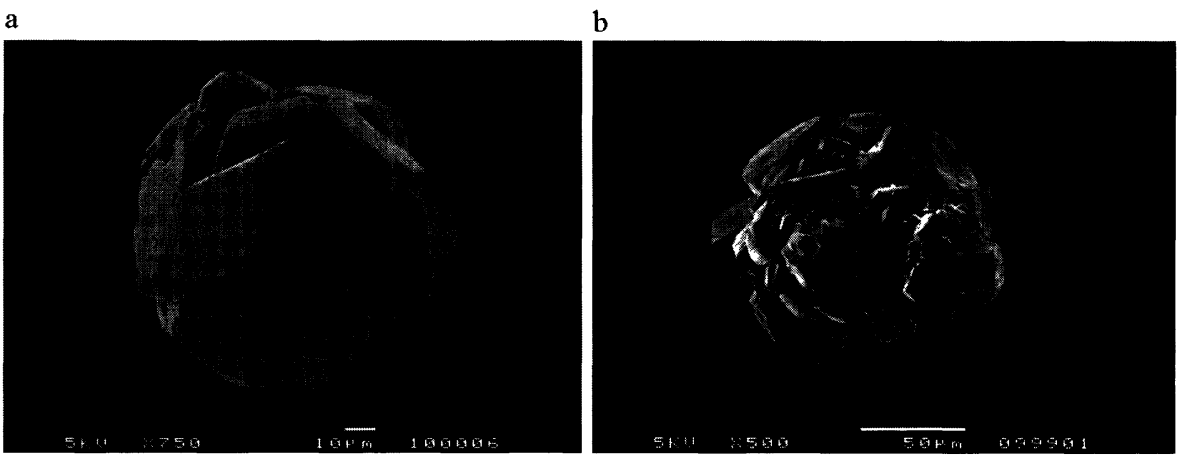

Fig. 8. - Hydrargillite: a) HR-type; b) HM-type.

This information can be obtained easily by optical microscopy. SEM provides more insight into the complexity of agglomerates, at the expense of the time required for image capture. It can be seen that there is a relation between the degree of agglomeration and the simplicity.

Similarly the descriptor CI can be used to have a rapid quantification of the degree of agglomeration, as shown in Figure 7. The degree of agglomeration is related to process conditions such as initial seeding, as shown in the following example (cf. Sect. 4.3).

4.3 GRINDING. - Figure 8 presents typical HR and HM hydrargillite agglomerates. Table III gives the morphological characteristics over samples of 70 particles observed by SEM. The differences in morphology results from differences into the crystallization process: a single initial 
Table III. - Comparison of the morphology of HM and HR particles (observation by SEM).

\begin{tabular}{|c|c|l|l|c|c|c|c|}
\hline Type & $D_{\text {eq }}(\mu \mathrm{m})$ & $F_{\max } / F_{\min }$ & $F_{\max } / F_{\text {eq }}$ & $\Omega_{1}$ & $\Omega_{2}$ & $\xi$ & $X_{\max }(\mu \mathrm{m})$ \\
\hline HR & 100 & 1.34 & 1.18 & 0.75 & 0.05 & 0.26 & 23 \\
\hline HM & 120 & 1.25 & 1.16 & 1.76 & 0.06 & 0.10 & 15 \\
\hline
\end{tabular}

seeding for HR and a controlled seeding for HM. In this case similar 2D-descriptors are found for both samples but the 3D-descriptors express the fact that $\mathrm{HM}$ agglomerates are constituted of a larger number of smaller crystals than HR. The fact that $\Omega_{2}$ and CI are not discriminative is due to the high degree of agglomeration, which tends to decrease the concavity of the silhouette. In consequence of their different structures these hydrargillites exhibit also different behavior in the grinding process: HM requires more energy for breakage than HR [11]. Finally the shape of fragments produced during grinding can also be examined to help to understand the phenomena taking place in the grinding chamber [12].

\section{Conclusions}

The quantification of particle shape using methods based on image analysis is nowadays available. Depending upon the particle size optical microscopy or SEM can be used. In the general case, i.e. when a broad shape range is expected, a set of shape descriptors has been shown to provide a sufficient description of the morphology of crystalline particles. In specific cases, special procedures can be sought to have a more precise description of the habit $[7,13]$.

It is clear that, actually, the off-line treatment rate is not high enough to reach the statistical accuracy obtained by classical particle sizers on large samples. But those particle sizers, although providing shape-dependent size measurements, cannot give any information of this shape. Optical microscopy can be used on-line, although the problem of automatic sampling is far to be fully solved. There is also hints of the possible development of in-situ microscopes [14], especially for application in crystallization. In spite of those difficulties the information on morphology is of prime importance for researchers and production engineers and should be more systematically sought and used for process improvement.

\section{References}

[1] Tanguy D. and Marchal P., Relations between the properties of particles and their process of manufacture, Chem. Eng. Res. Design 74 (1996) 715-722.

[2] Delubac, G. and Valenchon P., Le broyage dans l'industrie minérale, Récents Progrès en Génie des Procédés 10 (1996) 1-6.

[3] Kaye B.H., Clark G.G. and Liu Y., Characterizing the structure of abrasive fine particles, Part. Part. Syst. Charact. 9 (1992) 1-8.

[4] Riebel U., Kofler V. and Löffler F., Shape characterization of crystals and agglomerates, Part. Part. Syst. Charact. 8 (1991) 48-54.

[5] Coster M. and Chermant J.L., Précis d'analyse d'images (Les Presses du CNRS, Paris, 1989). 
[6] Gonzalez R.L. and Woods R.E., Digital Image Processing (Addison-Wesley, Reading, MA, 1992).

[7] Pons M.N. and Vivier H., Crystal characterization by quantitative image analysis, AIChE Symp Series, Particle design via crystallization 284 (1991) 88-95.

[8] Vivier H., Marcant B. and Pons M.N., Morphological shape characterization: application to oxalate crystals, Part. Part. Syst. Charact. 11 (1994) 150-155.

[9] Houcine I., Plasari E., David R. and Villermaux J., Influence of mixing characteristics on the quality and size of precipitated calcium oxalate in a pilot scale reactor, Chem. Eng. Res. Design 75 (1996) 252-256.

[10] Pons, M.N., Vucak M., Vivier H., Bernard-Michel B., Testa J.P., Aoun M. and Plasari E., Quantification of process conditions effects on particle shape during precipitation, Proc. 5th World Congress Chem. Eng. 5 (1996) 669-674.

[11] Lecoq O., Mebtoul M., Chouteau N. and Guigon P., Test de caractérisation de la broyabilité de différents matériaux granulaires, Récents Progrès en Génie des Procédés 10 (1996) 31-36.

[12] Rolland T, Pons M.N., Vivier H., Dodds J.A. and Thomas A., Analyse quantitative de la forme des particules durant le broyage: cas de l'hydrargillite, Récents Progrès en Génie des Procédés 10 (1996) 111-116.

[13] Puel F., Marchal P. and Klein J.P., Habit transient analysis in industrial crystallization using two dimensional crystal sizing technique, Chem. Eng. Res. Design 75 (1996) 193-205.

[14] Suhr H., Welnert G., Schneider K, Bittner C., Scholz T., Geissler P., Jähne B. and Schepper T., In-situ microscopy for on-line characterization of cell-populations in bioreactors, including cell concentration measurements, by depth from focus, Biotechnol. Bioeng. 47 (1995) 106-116. 